\title{
Candidose na medicina veterinária: um enfoque micológico, clínico e terapêutico
}

\author{
Candidosis on veterinary medicine: a mycological, clinical and therapeutic approuch
}

\author{
Erika Helena Salles de Brito ${ }^{I^{*}}$ Raquel Oliveira dos Santos Fontenelle ${ }^{\mathrm{I}}$ \\ Raimunda Sâmia Nogueira Brilhante ${ }^{\mathrm{II}}$ Rossana de Aguiar Cordeiro ${ }^{\mathrm{II}, \mathrm{III}}$ José Júlio Costa Sidrim ${ }^{\mathrm{II}}$ \\ Marcos Fábio Gadelha Rocha',II
}

\section{- REVISÃO BIBLIOGRÁFICA -}

RESUMO

O gênero Candida é composto por leveduras que vivem como comensais na microbiota de homens e animais. Em geral, não causam nenhum dano aos seus hospedeiros, entretanto, em virtude de desequilíbrios nas defesas química, física e imunológica, esses microrganismos podem se tornar patogênicos. Infecções por Candida spp. são pouco frequentes na Medicina Veterinária no entanto, nos últimos anos, tem sido observado aumento considerável de relatos de enfermidades causadas por essas leveduras, acometendo diferentes animais. Várias espécies do gênero são implicadas em quadros infecciosos, sendo a C. albicans a principal delas, seguida por $\boldsymbol{C}$. tropicalis e $\boldsymbol{C}$. parapsilosis. Considerando-se o potencial patogênico do gênero Candida, aliado ao surgimento de cepas resistentes a derivados azólicos, in vitro, o presente trabalho se propôs a realizar detalhada revisão de literatura, abordando os aspectos clínico-laboratoriais, etiológicos e terapêticos da candidose na Medicina Veterinária.

Palavras-chave: Candida, candidose, veterinária, derivados azólicos e resistência.

\section{ABSTRACT}

The Candida genus is composed by yeasts that live as commmensal on human and animals' microbiota. In general, they do not cause any damage to their hosts. However, due instability on chemical, physical and immunological defenses, these microorganisms can become pathogens.
Candida spp. infections are rare on Veterinary Medicine. However, on the last years, a considerable raise of illness caused by these yeasts has been related on varied animal species. Several species of this genus has been mentioned as responsible for infectious diseases in animals, being $\mathbf{C}$. albicans the main of them, followed by $C$. tropicalis and $C$. parapsilosis. Considering the pathogenic role of the genus Candida, allied to the emerging of resistant strains to the azole derivatives, in vitro, the present research proposed to perform a detailed review, approaching clinic-laboratorial, etiologic and therapeutic aspects of the candidosis on Veterinary medicine.

Key words: Candida, candidiasis, veterinary, azoles and resistance.

\section{INTRODUÇÃO}

O gênero Candida é composto por leveduras que vivem como comensais na microbiota de homens e animais. Em geral, não causam nenhum dano aos seus hospedeiros. Entretanto, em virtude de distúrbios nas proteções física, química e imunológica, esses microrganismos podem se tornar patogênicos e causar enfermidades, denominadas candidoses (MUELLER et al., 2002; MORETTI etal., 2004; SIDRIM \& ROCHA, 2004; GARCIA et al., 2007).

IFaculdade de Veterinária, Programa de Pós-graduação em Ciências Veterinárias, Universidade Estadual do Ceará (UECE), Fortaleza, CE, Brasil. Endereço para correspondência: Av. Rui Barbosa, 3333, Apt 201-C, Joaquim Távora, 60115-222, Fortaleza, CE, Brasil. E-mail: sallesbrito@yahoo.com.br.

IIDepartamento de Patologia e Medicina Legal, Faculdade de Medicina, Centro Especializado em Micologia Médica, UECE, Fortaleza, CE, Brasil.

IIIDepartamento de Biologia, UECE, Fortaleza, CE, Brasil. 
Infecções por Candida spp. em animais são pouco frequentes. No entanto, nos últimos anos, tem sido observado um aumento considerável de relatos de infecções por essas leveduras, com diferentes manifestações clínicas e acometendo variadas espécies animais (DUARTE et al., 2001; PRESSLER et al., 2003; LINEK, 2004; MORETTI et al., 2004; KUWAMURA et al., 2006; FULLERINGER et al., 2006; KIVARIA \& NOORDHUIZEN, 2007).

De acordo com a literatura, a C. albicans é a espécie mais frequentemente envolvida em casos de candidoses em animais (VELASCO, 2000; MORETTI et al., 2004; JIN \& LIN, 2005; JADHAV \& PAL, 2006; KIVARIA\& NOORDHUIZEN, 2007). No entanto outras espécies de Candida, tais como $\boldsymbol{C}$. tropicalis, $\boldsymbol{C}$. parapsilosis, dentre outras, também são citadas como agentes de tais infecções (MUELLER et al., 2002; PRESSLER et al., 2003; OZAWA et al., 2005; KIVARIA \&NOORDHUIZEN, 2007).

Diferentes drogas antifúngicas são utilizadas para o tratamento de candidoses em animais, mas a atividade dessas drogas vai dependerá da sensibilidade da cepa, tendo sido relatados alguns casos de cepas pouco sensíveis ou até resistentes a derivados azólicos (ROCHETTE et al., 2003; OZAWA et al., 2005; VANDEPUTTE et al., 2005; BRITO et al., 2007; LASSA \& MALINOWSKI, 2007).

Em virtude da escassez de informações sobre as características fenotípicas, moleculares, bem como do perfil de sensibilidade a drogas antifúngicas de cepas de Candida spp. oriundas de animais e levando-se em consideração o potencial patogênico do gênero Candida e o surgimento de cepas resistentes a derivados azólicos in vitro, o presente trabalho se propôs a realizar detalhada revisão de literatura, abordando os aspectos clínicolaboratoriais, etiológicos e terapêuticos da candidose na Medicina Veterinária.

Importância de Candida spp. na Medicina Veterinária

Como parte da microbiota animal

O isolamento de espécies de Candida a partir da microbiota de animais saudáveis, em especial os cães, é pouco relatado. Sabe-se, no entanto, que espécies do gênero habitam sítios como tubo digestivo, mucosas e pele de variados animais, incluindo muitos pássaros (CAFARCHIA et al., 2006). Dentre todas as Candida spp., a C. albicans é a mais presente, podendo ser isolada principalmente dos sistemas gastrintestinal, respiratório e genital, tendo predileção pela superfície de mucosas e pelas áreas de junções mucocutâneas de animais de sangue quente (ELAD et al., 1998; FERREIRO et al., 2002; BRITO et al., 2005; JADHAV \& PAL, 2006; GARCIA et al., 2007).
No Brasil, PAIXÃO et al. (2001), pesquisando fungos sapróbios em cães e gatos, relataram o isolamento de Candida spp. em 6,8\% dos animais analisados. SOUSA \& SIQUEIRA (2003) detectaram a presença de C. albicans no intestino de bovinos. Segundo esses autores, a presença desta levedura como sapróbio está condicionada a vários fatores, sendo o principal a presença de certas fontes de nutrientes.

Leveduras do gênero Candida também são encontradas como parte da microbiota do trato digestivo de diversas aves, tais como pombos, perus, aves de rapina, aves migratórias, aves industriais, drentre outras (CAFARCHIA et al., 2006, FULLERINGER et al., 2006; CAFARCHIA et al., 2008). De acordo com CARFACHIA et al., (2006), as aves transportam em sua cloaca leveduras potencialmente patogênicas, sendo capazes de disseminar esses fungos no ambiente, o que é um problema quando se trata de aves criadas em confinamento (FULLERINGER et al., 2006). Vale salientar ainda que leveduras presentes na microbiota desses animais tem ganhando maior importância na micologia médica ao longo das duas últimas décadas, em particular a criptococose e candidose, relatadas com maior frequência, especialmente em pacientes imunocomprometidos (VELASCO, 2000). C. albicans, C. tropicalis, C. incospicua, C. pelliculosa, C. famata, C. parapsilosis e $\boldsymbol{C}$. guilliermondii são espécies já isoladas a partir de aves saudáveis (CARFACHIA et al., 2006; GARCIA et al., 2007).

É importante salientar que conhecer os microrganismos que vivem como sapróbios em homens e animais é essencial, visto que, havendo um desequilíbrio no binômio parasita-hospedeiro, eles podem tornar-se agentes responsáveis por infecções e nesses casos, faz-se necessária a diferenciação entre um ser patogênico ou apenas constituinte da microbiota e isso inclui as espécies de Candida que vivem como comensais (ELAD etal., 1998; SIDRIM\& ROCHA, 2004).

\section{Como patógeno}

As espécies de Candida que vivem como sapróbias apresentam potencial patogênico que pode se manifestar em decorrência de um desequilíbrio do binômio parasita-hospedeiro, resultante de alterações nos mecanismos de defesa do portador ou por comprometimento das barreiras anatômicas de proteção (MUELLER et al., 2002; MORETTI et al., 2004; SIDRIM \& ROCHA, 2004; WEIG \& BROWN, 2007). Alguns fatores estão relacionados com essa característica de patogenicidade, tais como: capacidade de crescer a $37^{\circ} \mathrm{C}$; pleomorfismo, cujo papel é importante 
nos processos iniciais de invasão tecidual; produção de alguns metabólitos, que podem desencadear manifestações alérgicas do tipo imediato e tardio; produção de adesinas e de enzimas hidrolíticas, tais como proteinases e fosfolipases, consideradas fatores importantes de virulência do gênero e sendo produzidas pelas mais variadas espécies de Candida (SIDRIM \& ROCHA, 2004; KUMAR et al., 2006; CAFARCHIA et al., 2008).

$\mathrm{Na}$ Medicina Veterinária, são fatores predisponentes a infecções por Candida: idade, presença de doenças autoimunes, Diabetes mellitus, uso de corticosteroide, antibioticoterapia, cateterismo venoso e urinário e administração de nutrição parenteral (VELASCO, 2000; HESELTINE et al., 2003; MORETTI et al., 2004; KIVARIA \& NOORDHUIZEN, 2007). Os sítios anatômicos mais acometidos são: pele, unhas, ouvido, trato urinário, sistema gastrintestinal e reprodutor (HESELTINE et al., 2003; MORETTI et al., 2004; JIN \& LIN, 2005; GARCIA et al., 2007; KIVARIA \& NOORDHUIZEN, 2007).

Enfermidades provocadas por Candidas geralmente acometem apenas animais imunocomprometidos (PRESSLER et al., 2003; HESELTINE et al., 2003) e em pequenos animais, como cães e gatos, não são muito descritas. Em casos de quadros cutâneos, esse fato se justifica porque as lesões, na maioria das vezes, não são atribuídas a leveduras e sim a fungos filamentosos, bactérias e parasitas (RAPOSO et al., 1996). Por isso, MORETTI et al. (2004) chamam a atenção para a necessidade da realização de diagnóstico diferencial, associando o diagnóstico clínico ao laboratorial. Relatos de candidose em animais são descritos em diferentes partes do mundo, acometendo diversas espécies e com quadros clínicos variados (OCHIAI et al., 2000; DUARTE etal., 2001; MUELLER etal., 2002; PRESSLER et al., 2003; LINEK et al., 2004).

O primeiro relato de candidose, em cães, data de 1949 e se tratou de um caso de dermatomicose por C. albicans (REICH \& NECHTOW, 1949). No Brasil, há relatos da presença de espécies do gênero, causando quadros de otite (DUARTE et al., 2001), infecção intestinal em bovinos (SOUZA \& SIQUEIRA, 2003) e dermatomicose em cães (RAPOSO et al., 1996).

Candidoses são frequentemente associadas à morbidade e mortalidade de aves. Estas enfermidades têm como fatores predisponentes stress, idade, antibióticoterapia prolongada e status imune do animal (BALASUBRAMANIAM \& SUKUMAR, 2007). A flora normal do trato gastrintestinal das aves tem efeito inibitório sobre o crescimento de Candida spp. assim, qualquer desequilíbrio da microbiota digestiva, pelo uso incorreto de antibióticos por exemplo, ou por mudanças no $\mathrm{pH}$ gastrintestinal pode resultar na proliferação de fungos (GARCIA et al., 2007). Dessa forma, as Candidas são frequentemente associadas com problemas gastrointestinais, principalmente em aves jovens. Isso se deve ao sistema imune estar imaturo ou ao desenvolvimento incompleto das defesas gastrointestinais. Infecções sistêmicas, apesar de pouco frequentes, também podem acontecer (VELASCO, 2000; BALASUBRAMANIAM \& SUKUMAR, 2007; GARCIA et al., 2007; SCULLION \& SCULLION, 2007).

O principal agente envolvido na candidose em aves é a $\boldsymbol{C}$. albicans. O desequilíbrio populacional dessas leveduras leva ao aparecimento da doença, principalmente no sistema digestivo, podendo acometer o sistema reprodutivo e os olhos e tornar-se sistêmica (VELASCO, 2000; BALASUBRAMANIAM \& SUKUMAR, 2007; GARCIA et al., 2007).

A inflamação da glândula mamária é o mais importante problema sanitário em rebanhos bovinos leiteiros. A incidência de mastite devido à Candida spp. é geralmente muito baixa em vacas leiteiras. No entanto, KIVARIA \& NOORDHUIZEN (2007) relatam que ao longo de 31 anos as mastites casadas por $\boldsymbol{C}$. albicans aumentaram sua ocorrência de $\leq 1 \%$ para $\geq 17 \%$. Vale salientar ainda que essa enfermidade apresenta impacto econômico negativo sobre a rentabilidade da pecuária mundial, tanto pela redução da produtividade, quanto pelo aumento nos custos dos tratamentos.

De acordo com SANTOS \& MARIN (2005),

as Candidas constituem a terceira maior causa infecciosa de mastites no Brasil, e várias podem ser as fontes de contaminação, tais como: pele e secreção das tetas, mãos de ordenhadores, máquinas de ordenha, instrumentos de tratamento, condições higiênicas do ambiente, alimentos, dentre outras (KIVARIA \& NOORDHUIZEN, 2007). MOTA et al. (1999) identificaram o ordenhador como a fonte de infecção de casos de mastite por Candida spp. em bovinos. De acordo com a literatura, a antibióticoterapia e infusão intramamária de antibióticos, muitas vezes aplicadas sem análise microbiológica do leite, também são fatores predisponentes importantes para essa enfermidade (KRUKOWSKI et al., 2000; SANTOS \& MARIN, 2005).

Diferentes espécies do gênero já foram relatadas causando enfermidades em animais, tais como: C. guilliermondii, responsáveis por quadros de dermatomicoses em cães (MUELLER et al., 2002); C. tropicalis, C. glabrata, e C. krusei, causando quadros diarréicos em bezerros (ELAD et al., 1998) e $\boldsymbol{C}$. parapsilosis, agente de dermatomicose em cães (DALE, 1972). As espécies C krusei, C. rugosa, C. albicans, $C$. 
guilliermondii, C. parapsilosis, C. zeulanoide, C. famata, C. kefyr, C. ciferrii, C. humicola, C. rugosa, Candida pelliculosis e C. tropicalis já foram identificadas como agentes de mastite clínica e subclínica em bovinos (KRUKOWSKI et al., 2000; SANTOS \& MARIN, 2005; KIVARIA \& NOORDHUIZEN, 2007).

PRESSLER et al. (2003) isolaram espécies de Candida, causando infecção urinária em 13 cães e sete gatos, entre as quais estavam: $\boldsymbol{C}$. albicans, $\boldsymbol{C}$. tropicalis, C. rugosa, C. krusei, C. parapsilosis e $C$. glabrata. KOZAK et al. (2003) isolaram cepas de Candida spp., em especial C. krusei, em lesões superficiais na pele, em 5\% de 100 cães analisados e, mais recentemente, OZAWA et al. (2005) isolaram $\boldsymbol{C}$. tropicalis como agente de um quadro de cistite em um cão.

De acordo com a literatura, a C. albicans é a espécie mais comum em casos de candidoses em animais, sendo responsável por diversos quadros clínicos, como otite (DUARTE et al., 2001), infecção intestinal (OCHIAI et al., 2000), septicemia (HESELTINE et al., 2003), dermatomicose, infecção urinária, dentre outros (RAPOSO et al., 1996; KOZAK et al., 2003; PRESLLER et al., 2003; MORETTI et al., 2004; JIN \& LIN, 2005).

Casos de endoftalmite causados por $\boldsymbol{C}$. albicans são ocasionalmente relatados em animais domésticos e resultam da difusão hematogênica ou são secundários a uma inflamação primária da córnea pela levedura, com inoculação diretamente dentro do olho (GERDING et al., 1994; LINEK, 2004).

Apesar de serem tidas como oportunistas, KOZAK et al. (2003) isolaram espécies de Candida causando dermatomicose em animais jovens, livres de desordens imunológicas, destacando-se $\boldsymbol{C}$. albicans e C. krusei dentre as espécies observadas. Ademais, BROWN et al. (2005) descreveram a presença de candidose sistêmica em um cão sem nenhuma deficiência imunológica aparente.

Com relação ao aspecto clínico das candidoses em pequenos animais, em cães e gatos acometidos por infecção urinária causadas por Candida spp., é possível observar quadros de disúria, hematúria, aumento da frequência de miç̧ão, anorexia, depressão e pirexia, sendo este último o principal sintoma (JIN \& LIN, 2005).

As lesões clássicas em casos dermatomicoses por Candida spp. apresentam contorno irregular e são levemente edemaciadas, com vesículas preferencialmente localizadas em áreas com dobras cutâneas, como: espaços interdigitais, prepúcio e região perianal. Pode haver, no entanto, a ocorrência de lesões com alopecia, crostas, úlceras e edema (MORETTI et al., 2004).

As otites por Candida apresentam a mesma sintomatologia daquelas causadas por outros microrganismos, como bactérias, ou seja, é possível observar a presença de inflamação, prurido, dor, descamação e edema (MOTA et al., 1999).

A candidose em aves caracteriza-se pelo aparecimento de placas esbranquiçadas, localizadas em geral no interior da cavidade bucal e especialmente, no papo, pela formação de placas pseudomembranosas necróticas na cavidade oral e no trato digestivo e pela presença de material caseoso que dificulta a deglutição e respiração. Penas arrepiadas, dificuldades de ingestão de alimentos, diarreia, dispneia, anorexia, prostração, regurgitação, vômito, perda de peso, esofagite e espessamento da parede do esôfago são sintomas visíveis. Casos graves podem provocar deformidades no bico. Em casos de infecções sistêmicas, são observados sinais no sistema nervoso central, bem como lesões típicas de candidose gastrointestinal (VELASCO, 2000; BALASUBRAMANIAM \& SUKUMAR, 2007).

\section{Diagnóstico}

O diagnóstico laboratorial das espécies do gênero Candida consiste, inicialmente, da confecção de lâminas com base na amostra clínica, com hidróxido de potássio (exame direto), que permite melhor visualização de estruturas fúngicas, ou por meio da coloração de Gram, bem como de posterior repique da mesma amostra em meios de cultura clássicos: ágar Sabouraud, ágar Sabouraud com cloranfenicol e ágar Sabouraud acrescido de cloranfenicol e cicloheximida. Após o crescimento do fungo nos meios de cultura, são realizadas provas bioquímicas, nutricionais e morfológicas adequadas para identificação das espécies do gênero (SIDRIM \& ROCHA, 2004).

Quando cultivadas, in vitro, em meios de cultura adequados, as Candidas crescem bem dentro de 48 horas, entre temperaturas de 25 e $37^{\circ} \mathrm{C}$ (KOEHLER et al., 1999). Com relação à microscopia, se lâminas forem preparadas diretamente com um fragmento da colônia ou amostras clínicas positivas, apenas os blastoconídios serão visualizados.

Microcultivos em placa de Petri com CornMeal, acrescidos de Tween 80 , são realizados com o intuito de permitir melhor visualização da disposição das estruturas fúngicas típicas de cada espécie, sendo estes, na maioria das vezes, suficientes para identificar o microrganismo; por exemplo, cepas da espécie $\boldsymbol{C}$. albicans, apresentam, no microcultivo, pseudo-hifas, hifas verdadeiras, blastoconídios formando cachos, 
bem como clamidoconídios terminais, características peculiares à espécie (RAPOSO et al., 1996; KOEHLER et al., 1999).

Na rotina laboratorial, diferentes testes são utilizados para diferenciar bioquimicamente as espécies de Candida, tais como: assimilação de nitrogênio e de carboidratos (auxonograma), fermentação de carboidratos (zimograma), prova da ureia e teste do tubo germinativo (SIDRIM \& ROCHA, 2004).

De acordo com KURTZMAN \& FELL(1998), as espécies de Candida são classificadas em 12grupos com base em suas características fisiológicas, principalmente no que se refere à assimilação de fontes de carbono e nitrogênio. Muitas espécies têm sido classificadas em mais de um grupo. No entanto, a maioria das espécies de Candida de interesse clínico, no que se refere ao homem e aos animais, pertence ao grupo VI, tais como C. albicans e C. tropicalis.

O auxonograma consiste na capacidade que uma levedura apresenta de crescer aerobiamente na presença de determinado carboidrato, fornecido como única fonte de carbono. Os seguintes carboidratos são utilizados: inulina, ramnose, L-arabinose, celobiose, dextrose, sacarose, rafinose, dulcitol, melibiose, trealose, galactose, maltose, xilose, inositol e lactose.

As espécies do gênero Candida apresentam um perfil de assimilação de carboidratos diferente, e a leitura é feita, durante 24 a 96 horas, mediante visualização de halos de crescimento que se formam em volta do carboidrato assimilado. Dessa forma, cepas de $\boldsymbol{C}$. albicans apresentam resultado positivo para glicose, galactose, xilose, trealose e maltose e resultado variável para L-arabinose e sacarose. A C. tropicalis é capaz de assimilar glicose, galactose, xilose, trealose e maltose, podendo assimilar ou não sacarose. Quanto à C. parapsilosis, esta assimila glicose, galactose, sacarose, maltose, trealose, xilose, arabinose e rafinose, sendo esta última variável (HOOG et al., 2000; SIDRIM \& ROCHA, 2004).

No zimograma, é avaliada a capacidade que a levedura tem de fermentar determinado açúcar em baixas tensões de oxigênio. Uma suspensão da levedura é colocada em um tudo de ensaio contendo meio de cultura líquido e um tubo de Durhan invertido. A positividade é dada pela produção de gás carbônico, que fica contido no interior do tubo de Durhan, formando bolhas visíveis. Geralmente, os carboidratos utilizados nesse teste são dextrose, maltose, sacarose, galactose, lactose e trealose, mas outros podem ser empregados. Sabe-se que, de forma geral, a espécie $\boldsymbol{C}$. albicans é capaz de fermentar glicose e maltose e apresenta resultado variável para galactose e trealose; já cepas de $\boldsymbol{C}$. tropicalis são positivas para glicose, galactose, trealose e maltose, podendo fermentar ou não sacarose. $C$. parapsilosis fermenta glicose, e a galactose é variável (HOOG et al., 2000; SIDRIM \& ROCHA, 2004). A experiência em trabalhos realizados no Centro Especializado em Micologia Médica, com espécimes de origem animal, mostra que as espécies mais encontradas são $\boldsymbol{C}$. albicans, $\boldsymbol{C}$. tropicalis e $\boldsymbol{C}$. parapsilosis, por esse motivo foram descritos os principais aspectos fisiológicos das mesmas.

Existem também métodos automatizados para identificação das principais espécies do gênero, os quais são de realização e interpretação fáceis, além de oferecer o resultado em tempo menor. São kits tais como API 20C Aux (bioMerieux-Vitek) e API 32C, que se baseiam na capacidade assimilativa de substratos bioquímicos e enzimáticos pelas leveduras (KOEHLER et al., 1999).

Meios de cultura cromogênicos para Candida, tais como o BBLTM CHROMagar CandidaTM (Becton Dickinson) e ágar Candida ID2 (bioMérieux), facilitam bastante o diagnóstico de infecções por Candida spp., principalmente quando são candidoses sistêmicas (WEIG \& BROWN, 2007).

\section{Estratégias de tratamento}

Diferentes drogas antifúngicas são indicadas para o tratamento de infecções causadas por Candida spp., não existindo, no entanto, uma terapêutica padronizada (NOBRE et al., 2002). Recentemente os triazólicos têm recebido maior destaque, sobretudo o fluconazol e o itraconazol, ambos com largo espectro de ação e efeitos tóxicos bastante reduzidos. Entretanto, devido a sua frequente utilização, tem-se observado resistência entre os fungos, principalmente por espécies de Candida (NOBRE et al., 2002). De acordo com OZAWA et al. (2005), a atividade dessas drogas dependerá da sensibilidade da cepa em foco.

Em casos de infecção sistêmica por leveduras do gênero acometendo diferentes espécies animais, a anfotericina B demonstra ser bastante eficiente. Estudos demonstraram boa atividade da droga in vitro contra cepas de Candida spp. isoladas de bovinos com mastite. No entanto, esse é um fármaco pouco utilizado na rotina, em virtude do custo elevado e dos severos efeitos colaterais (ROCHETTE et al., 2003; OZAWA et al., 2005). Outros fármacos indicados para o tratamento de vacas acometidas de mastite são o miconazol e clotrimazol, utilizados via intramamária, como também aplicação tópica de natamicina (NOBRE et al., 2002).

No que concerne à aplicação dos derivados azólicos, em casos de candidose superficial, um dos 
tratamentos indicados é o uso de cetoconazol duas vezes ao dia, associado com a utilização de xampu contendo clorexidina e miconazol, por um período de até seis semanas (MUELLER et al., 2002).

O cetoconazol apresenta espectro de atividade amplo, que engloba várias espécies de Candida e dermatófitos. No entanto, estudos relatam sua pouca eficiência in vitro, contra cepas de $\boldsymbol{C}$. tropicalis e C. albicans (ROCHETTE et al., 2003; BRITO et al., 2007). Quando usado, tal fármaco pode resultar em uma série de efeitos colaterais, como: inapetência, diarreia, depressão e alopecia, além de ser hepatotóxico. Esses efeitos são observados principalmente em animais jovens (ROCHETTE et al., 2003; OZAWA et al., 2005; BRITO et al., 2007).

Entre os derivados azólicos, utilizados para o tratamento de candidoses em pequenos animais, está também o fluconazol. De acordo com LINEK (2004), esse fármaco pode ser utilizado em cães para o tratamento de endoftalmites por Candida, devendo ser a primeira dose administrada por via oral e a segunda 24 horas depois. Apesar de bastante utilizado e apresentando bons resultados no tratamento contra candidoses, o fluconazol mostra-se impotente contra algumas espécies como: C. krusei e C. glabrata (VANDEN BOSSCHE et al., 2003; POSTERARO et al., 2006).

Em casos de infecção urinária causada por Candida, o itraconazol é um derivado azólico que pode ser utilizado, sendo administrado por via oral, uma vez ao dia, por até quatro semanas. Após esse período, KANO et al. (2002) relataram que não mais observaram a presença de leveduras na urina de um cão com tal enfermidade. Essa droga é bastante eficiente também em casos de candidoses sistêmicas e superficiais (ROCHETTE et al., 2003; OZAWA et al., 2005).

Uma preparação otológica contendo clotrimazol, que é um derivado imidazólico, é indicada para o tratamento de otites externas agudas e crônicas, em cães, causadas por fungos, incluindo Candida spp., sendo a utilização tópica de uma solução a $1 \%$ eficaz para o tratamento de otite externa por C. albicans (MOTA et al., 1999).

Para as aves acometidas de candidose, é indicado tratamento com nistatina. Vale salientar que, por não ser absorvido no sistema gastrintestinal, esse fármaco precisa agir por contato direto com as lesões. Em casos de candidose refratária, recomenda-se a utilização de antifúngicos sistêmicos, tais como: itraconazol, fluconazol ou anfotericina B (VELASCO, 2000; BALASUBRAMANIAM \& SUKUMAR, 2007).
Teste de sensibilidade a antifúngicos

Nos últimos anos, tem crescido o interesse pela busca do perfil de sensibilidade in vitro de cepas fúngicas (PEREA et al., 2001). Com esse intuito, em 1997, o Clinical and Laboratory Standards Institut (CLSI) (antigo National Committee for Clinical Laboratory Standards) aprovou os testes de micro e macrodiluição em caldo para testar a sensibilidade in vitro de fungos leveduriformes, por meio do documento M27-A, sendo este revisto em 2002 (M27-A2). Desta forma, parâmetros foram determinados para variáveis como: tamanho do inóculo, temperatura, duração de incubação, meio de cultura e critério de leitura.

Existe também um método comercial para testar a sensibilidade de cepas fúngicas, é o E-test ${ }^{\circledR}$, que consiste em uma fita plástica contendo fármaco em diferentes concentrações, expressas no reverso da tira. Esse teste reúne a vantagem da simplicidade de métodos baseados na difusão em ágar, já que esse é seu princípio, com as informações quantitativas fornecidas pelos métodos da diluição. Dessa forma, o E-test ${ }^{\circledR}$ poderia ser uma alternativa para a triagem de casos de rotina pela sua simplicidade; no entanto, padronizações ainda precisam ser estabelecidas para que este possa se tornar uma alternativa para a metodologia preconizada pelo CLSI (KOGA-ITO et al., 2008).

Apesar da metodologia já estabelecida, poucos são os trabalhos que testam a sensibilidade in vitro de cepas de Candida spp. isoladas de animais. OZAWA et al. (2005) utilizaram a técnica de microdiluição em caldo para testar a sensibilidade in vitro de uma cepa de $\boldsymbol{C}$. tropicalis, isolada da urina de um cão com cistite, a drogas como itraconazol e fluconazol, tendo sido a cepa sensível ao itraconazol, no entanto, apresentou valores elevados de sensibilidade para fluconazol.

BRITO et al. (2007) realizaram testes de sensibilidade in vitro com cepas de Candida spp. isoladas de cães e identificaram presença de resistência aos derivados azólicos: cetoconazol, itraconazol e fluconazol. Os valores de concentração inibitória mínima (CIM) encontrados foram os seguintes: para itraconazol e cetoconazol foi maior que $16 \mu \mathrm{g} / \mathrm{mL}$ para todas as cepas de $\boldsymbol{C}$. albicans e $66,7 \%$ das $\boldsymbol{C}$. tropicalis; o fluconazol apresentou CIM $>64 \mu \mathrm{g} \mathrm{mL}^{-1}$ para $80 \%$ das cepas de $\boldsymbol{C}$. albicans e $66,7 \%$ das cepas de $\boldsymbol{C}$. tropicalis.

A padronização de métodos de testes de sensibilidade in vitro se faz cada vez mais necessária, o que poderá tornar a escolha da terapêutica sempre mais adequada e eficiente. Além disso, é uma importante ferramenta para vigilância e monitoramento de cepas resistentes (BRITO et al., 2007). 
Resistência antifúngica

A resistência aos antifúngicos pode ser classificada de duas formas: resistência in vitro e resistência in vivo. A resistência in vitro pode ser subdividida ainda em resistência in vitro primária, chamada também de intrínseca ou inata, que se apresenta naturalmente no microrganismo; e resistência in vitro secundária, que aparece quando o microrganismo inicialmente sensível se faz resistente (BALKIS et al., 2002; SANGLARD \& ODSS, 2002; VANDEPUTTE et al., 2005). A resistência in vivo ocorre em virtude de fatores diferentes, como: farmacocinética da droga antifúngica, fatores dependentes do hospedeiro (estado imune, doenças de base, dentre outros) e fatores relacionados ao microrganismo, como virulência e resistência (BALKIS et al., 2002).

Diversos são os relatos de cepas de Candida isoladas de humanos resistentes in vivo e in vitro a fármacos antifúngicos, principalmente a derivados azólicos, sendo as espécies $\boldsymbol{C}$. albicans, $\boldsymbol{C}$. krusei e $\boldsymbol{C}$. glabrata as mais citadas (PEREA et al., 2001; SANGLARD \& ODSS, 2002; POSTERARO et al., 2006). Recentemente, cepas de $\boldsymbol{C}$. albicans e $\boldsymbol{C}$. tropicalis, oriundas de animais, apresentaram resistência in vitro a fluconazol, cetoconazol e itraconazol (OZAWA et al., 2005; BRITO et al., 2007).

Pontos de mutação no gen ERG11 e falha no acúmulo de antifúngicos azólicos têm sido identificados como as principais causas de resistência em isolados fúngicos pouco sensíveis a tais drogas. VANDEPUTTE et al. (2005) detectaram a superexpressão de gens responsáveis pelas bombas de efluxo em cepas de $\boldsymbol{C}$. tropicalis, e segundo os autores, a resistência nessa espécie pode ser induzida facilmente.

Modificações na interação da droga com a enzima-alvo também são citadas como causa de resistência em cepas fúngicas. Mutações desse gênero são descritas em cepas de C. albicans resistentes ao fluconazol. ASAI et al. (1999) demonstram com seus resultados que esse tipo de mutação acarreta em uma não perturbação da atividade da 14 a-demetilase pelo antifúngico, permitindo a mutantes a capacidade de produzir ergosterol normalmente.

PEREA et al. (2001) investigaram mecanismos moleculares que resultam na resistência a azólicos, em cepas de C. albicans resistentes a fluconazol. A análise realizada confirmou uma natureza multifatorial na resistência a tal fármaco, com a predominância de mecanismos como a "superexpressão" de gens que codificam as bombas de efluxo, detectada em $85 \%$ das cepas resistentes analisadas. Mutações como a substituição do aminoácido funcional e a superexpressão do gen, que codifica a enzima-alvo da droga, foram detectadas em 65 e $35 \%$ dos isolados, respectivamente. Em $75 \%$ dos isolados havia múltiplos mecanismos combinados.

Biologia molecular no estudo das candidoses Avanços obtidos na área da Biologia Molecular permitiram o desenvolvimento de métodos moleculares, extremamente eficientes, para a identificação de espécies e subespécies do gênero Candida, bem como para o monitoramento da emergência de cepas resistentes a antifúngicos, já que a avaliação genética é uma prova útil para definir os efeitos das drogas antifúngicas na célula fúngica e mecanismos de adaptação destas aos antifúngicos (CIRAK et al., 2003).

A análise molecular pode contribuir para melhor entendimento da patogênicidade desse grupo de microrganismos, bem como a tipificação de cepas pode fornecer informações sobre a origem e os mecanismos de transmissão e estabelecer relação entre isolados e suas propriedades de virulência (WEIG \& BROWN, 2007).

O PCR (Polymerase chain reaction) foi uma das primeiras técnicas descritas para tais aplicações, sendo muito eficiente na distinção de espécies de Candida. Outras técnicas, porém, surgiram com objetivo de potencializar a eficiência do PCR na identificação de microrganismos, como RAPD (Random amplified polymorphic DNA), AP-PCR (arbitrarily primed PCR), RFLP (Restriction Fragment length polymorphism), entre outras. Todas são utilizadas de forma eficiente na identificação de espécies do gênero Candida (CIRAK et al., 2003).

A aplicação de adventos moleculares para a Medicina Veterinária é muito escassa, e poucos são os relatos da utilização de tais técnicas para estudos epidemiológicos, de identificação e caracterização de espécies de Candida, isoladas de animais. Trabalhos como de KANO et al. (2002) e MORETTI et al. (2004) chamam atenção para esse fato. Os autores aplicaram técnicas moleculares distintas para identificação de cepas de Candida, agentes de infecções em animais. KANO et al. (2002) identificaram uma cepa de $\boldsymbol{C}$. albicans e uma de C. parapsilosis, provenientes da urina de cães com infecção urinária, pela análise do DNA ribossomal por PCR. Já MORETTI et al. (2004) optaram por uma reação de PCR-REA (Restriction Enzyme Analysis), mediante a qual identificaram uma cepa de $\boldsymbol{C}$. albicans responsável por um quadro de dermatomicose em um cão. Vale salientar que EDELMANN et al. (2005), em uma análise filogenética, concluíram que isolados de $\boldsymbol{C}$. albicans oriundos de humanos e de animais não apresentaram nenhuma 
distinção e que os animais podem ser considerados possíveis vetores desses microrganismos para seres humanos, principalmente imunocomprometidos.

Diversos autores incentivam o diagnóstico, por Biologia Molecular, de infecções invasivas por Candida, diretamente da amostra clínica, tais como sangue, soro, plasma, frascos de cultura de sangue, líquidos corporais e amostras de tecido (KLINGSPOR \& JALAL, 2006). O método de PCR, entretanto, é sensível para reações cruzadas com contaminantes, resultando em falso-positivos. Outros problemas metodológicos incluem a rígida parede celular de Candida spp., a presença de um baixo número de leveduras circulantes durante infecção sistêmica e Candidas provenientes da microbiota que podem estar contaminando a amostra clínica. Esses fatores, juntamente com a ausência de padronização para seleção e manipulação de amostras clínicas, extração de DNA e detecção do DNA-alvo, conduzem a resultados divergentes. Como consequência, os resultados moleculares não são reconhecidos e não há consenso no que diz respeito aos critérios para diagnóstico (WEIG \& BROWN, 2007).

\section{CONCLUSÕES}

Com base no crescente aumento da casuística de candidose na Medicina Veterinária, em especial na clínica de cães e gatos, e sabendo-se que os isolados de Candida spp. oriundos de humanos e de animais não apresentam distinção genotípica e ainda considerando-se que algumas cepas de Candida spp., isoladas de cães, têm se mostrado resistentes aos derivados azólicos, faz-se necessária maior vigilância epidemiológica. Os objetivos dessa vigilância são manter a saúde animal, bem como compreender melhor o papel dos animais como vetores em potencial destes microrganismos para o homem.

\section{REFERÊNCIAS}

ASAI, K. et al. Formation of azole-resistant Candida albicans by mutation of sterol 14á-demethylase P450. Antimicrobial Agents and Chemotherapy, v.43, p.1163-1169, 1999.

BALASUBRAMANIAM, A.; SUKUMAR, S. An overview on outbreaks of candidiasis in poultry. Tamilnadu Journal Veterinary \& Animal Sciences, v.3, n.3, p.121-123, 2007.

BALKIS, M.M. et al. Mechanisms of fungal resistance: an overview. Drugs, v.62, p.1025-1040, 2002.

BRITO, E.H.S. et al. Phenotypic characterization and in vitro antifungal sensitivity of Candida spp. and Malassezia pachydermatis strains from dogs. Veterinary Journal, v.174, p.147-153, 2007.
BROWN, M.R. et al. Systemic candidiasis in an apparently immunocompetent dog. Journal of Veterinary Diagnostic Investigation, v.17, p.272-276, 2005.

CAFARCHIA, C. et al. Role of birds of prey as carriers and spreaders of Cryptococcus neoformans and other zoonotic yeasts. Medical Mycology, v.44, p.485-492, 2006.

CAFARCHIA, C. et al. Phospholipase activity of yeasts from wild birds and possible implications for human disease. Medical Mycology, v.46, p.1-6, 2008.

CIRAK, M.Y. et al. Use of molecular methods in identification of Candida species and evaluation of fluconazole resistance. Memórias do Instituto Oswaldo Cruz, v.98, p.1027-1032, 2003.

CLINICAL AND LABORATORY STANDARDS INSTITUT (National Committee for Clinical Laboratory Standards). Reference method for broth dilution antifungal susceptibility testing of yeasts. Approved standard M27A2. Wayne: National Committee for Clinical Laboratory Standards, 51 p., 2002

DALE, J.E. Canine dermatosis caused by Candida parapsilosis. Veterinary Medicine \& Small Animal Clinician, v.67, p.548-549, 1972.

DUARTE, E.R. et al. Prevalence of yeasts and mycelial fungi in bovine parasitic otitis in the State of Minas Gerais, Brazil. Journal of Veterinary Medicine Series B-Infectious Diseases and Veterinary Public Health, v.48, p.631-635, 2001.

EDELMANN, A. et al. Genetic relationship between human and animal isolates of Candida albicans. Journal of Clinical Microbiology, v.43, p.6164-6166, 2005.

ELAD, D. et al. Yeasts in the gastrointestinal tract of reweaned calves and possible involvement of Candida glabrata in neonatal calf diarrhea. Mycopathologia, v.141, p.7-14, 1998.

FERREIRO, L. et al. Associações entre o isolamento de Candida albicans com a infecção pelo vírus da leucemia felina (FELV), tratamentos com corticosteróides ou antimicrobianos em gatos. Acta Scientiae Veterinariae, v.30, n.3, p.179-183, 2002.

FULLERINGER, S.L. et al. Evolution of the environmental contamination by thermophilic fungi in a turkey confinement house in France. Poultry Science, v.85, p.1875-1880, 2006.

GARCIA, M.E. et al. Fungal flora in the trachea of birds from a wildlife rehabilitation centre in Spain. Veterinarni Medicina, v.52, n.10, p.464-470, 2007.

GERDING, P.A. et al. Ocular and disseminated candidiasis in an imunosuppressed cat. Journal of the American Veterinary Medical Association, v.204, p.1635-1638, 1994.

HESELTINE, J.C. et al. Systemic candidiasis in a dog. Journal of the American Veterinary Medical Association, v.223, p.821-824, 2003.

HOOG, G.S. et al. Atlas of clinical fungi. 2.ed. Baarn/Delft: Centraalbureau voor Schinmelculture/Universitat Rovira i Virgilli, 2000. 1126p.

Ciência Rural, v.39, n.9, dez, 2009. 
JADHAV, V.J.; PAL, M. Canine mycotic stomatitis due to Candida albicans. Revista Iberoamericana de Micologia, v.23, p.233-234, 2006.

JIN, Y.; LIN, D. Fungal urinary tract infections in the dog and cat: a retrospective study (2001-2004). Journal of the American Animal Hospital Association, v.41, p.373-381, 2005 .

KANO, R. et al. Detection and identification of the Candida species by $25 \mathrm{~S}$ ribosomal DNA analysis in the urine of candidal cystitis. Journal of Veterinary Medical Science, v. 64 p.115-117, 2002

KIVARIA, F.M.; NOORDHUIZEN, J.P.T.M. A retrospective study of the aetiology and temporal distribution of bovine clinical mastitis in smallholder dairy herds in the Dar es Salaam region of Tanzania. Veterinary Journal, v.173, p.617-622, 2007.

KLINGSPOR, L.; JALAL, S. Molecular detection and identification of Candida and Aspergillus spp. from clinical samples using real-time PCR. Clinical Microbiology and Infection, v. 12,p.745-753, 2006.

KOEHLER, A.P. et al. Simple, reliable, and cost-effective yeast identification scheme for the clinical laboratory. Journal of Clinical Microbiology, v.37, p.422-426, 1999.

KOGA-ITO, C.Y. et al. Comparison between E-test and CLSI broth microdilution method for antifungal susceptibility testing of Candida albicans oral isolates. Revista do Instituto de Medicina Tropical de São Paulo, v.50, n1, p7-10, 2008.

KOZAK, M. et al. Study of the dermatophytes in dogs and the risk of human infection. Bratisl Lek Listy, v.104, p.211217,2003

KUMAR, C.P. et al. Phospholipase and proteinase activities of clinical isolates of Candida from immunocompromised patients. Mycopathologia, v.161, p.213-218, 2006.

KRUKOWSKI, H. et al. Survey of yeast mastitis in dairy herds of small-type farms in the Lublin. Mycopathologia, v.150, p.5-7, 2000.

KURTZMAN, C.P.; Fell, J.W. The yeasts: a taxonomic study 4.ed. Amsterdam: Elsevier Science, 1998. 1055p

KUWAMURA, M. et al. Systemic candidiasis in a dog, developing spondylitis. Journal of Veterinary Medical Science, v.68, p.1117-1119, 2006.

LASSA, H.; MALINOWSKI, E. Resistance of yeasts and algae isolated from cow mastitic milk to antimicrobial agents. Bulletin of the Veterinary Institute in Pulawy, v.51, p.575578, 2007.

LINEK, J. Mycotic endophthalmitis in a dog caused by Candida albicans. Veterinary Ophthalmology, v.7, p.159-162, 2004.

MORETTI, A. et al. Diffuse cutaneous candidiasis in a dog. Diagnosis by PCR-REA. Revista Iberoamericana de Micologia, v.21, p.139-142, 2004.

MOTA, R.A. et al. Bovine mastitis caused by Candida sp.: epidemiological and clinical aspects. Revista Brasileira de Ciência Veterinária, v.6, n.2, p.101-103, 1999.
MOTA, R.A. et al. Eficácia do otomax no tratamento da otite bacteriana e fúngica de cães. Vet News, 1999. Disponível na Internet www.schering-plough.com.br. Online. Acesso em: 06 jan. 2007.

MUELLER, R.S. et al. Cutaneous candidiasis in a dog caused by Candida guilliermondii. Veterinary Record, v.150, p.728730, 2002.

NOBRE, M.O. et al. Drogas antifúngicas para pequenos e grandes animais. Ciência Rural, v.32, p.175-184, 2002.

OCHIAI, K. et al. Intestinal candidiasis in a dog. Veterinary Record, v.146, p.228-229, 2000 .

OZAWA, H. et al. Rapid identification of Candida tropicalis from canine cystitis. Mycopathologia, v.160, p.159-162, 2005.

PAIXÃO, G.C. et al. Dermatophytes and saprobe fungi isolated from dogs and cats in the city of Fortaleza, Brazil. Arquivo Brasileiro de Medicina Veterinária e Zootecnia, v.51, n.5, p.568-573, 2001 .

PEREA, S. et al. Prevalence of molecular mechanisms of resistance to azole antifungal agents in Candida albicans strains displaying high-level fluconazole resistance isolated from human immunodeficiency virus-infected patients. Antimicrobial Agents and Chemotherapy, v.45, p.2676-2684, 2001.

POSTERARO, B. et al. Azole resistance of Candida glabrata in a case of recurrent fungemia. Journal of Clinical Microbiology, v.44, p.3046-3047, 2006.

PRESSLER, B.M. et al. Candida spp urinary tract infections in 13 dogs and seven cats: predisposing factors, treatment, and outcome. Journal of the American Animal Hospital Association, v.39, p.263-270, 2003.

RAPOSO, B.R. et al. Candidíase cutânea em um canino. Revista da Faculdade de Zootecnia, Veterinária e Agronomia, v.2-3, p.11-14, 1996.

REICH, W.J.; NECHTOW, M.J. Canine genital moniliasis as a source of reinfection in the human female. Journal of the American Veterinary Medical Association, v.141, n.14, p.991, 1949

ROCHETTE, F. et al. Antifungal agents of use in animal health - practical applications. Journal of Veterinary Pharmacology and Therapeutics, v.26, p.31-53, 2003.

SANGLARD, D.; ODSS, F.C. Resistance on Candida species to antifungal agents: molecular mechanisms and clinical consequances. Lancet Infectious Diseases, v.2, p.73-85, 2002 .

SANTOS, R.C.; MARIN, J.M. Isolation of Candida spp. from mastitic bovine milk in Brazil. Mycopathologia, v.159, p.251253,2005 .

SCULliON, F.T.; SCULliON, M.G. Pathologic findings in racing pigeons (Columba livia domestica) with "Young Bird 
Sickness". Journal of Avian Medicine and Surgery, v.21, n.1, p.1-7, 2007.

SIDRIM, J.J.C.; ROCHA, M.F.G. Micologia médica à luz de autores contemporâneos. Rio de Janeiro: Guanabara Koogan, 2004. 338p.

SOUZA, W.A.; SIQUEIRA, A.M. Ocorrência de Candida albicans em intestinos de bovinos. Arquivo Brasileiro de Medicina Veterinária e Zootecnia, v.55, n.3, p.262-265, 2003.

VANDEN BOSSCHE, $\mathrm{H}$. et al. Antifungal agents of use in animal health - chemical, biochemical and pharmacological aspects. Journal of Veterinary Pharmacology and Therapeutics, v.26, p.5-29, 2003.

VANDEPUTTE, P. et al. Mechanisms of azole resistance in a clinical isolate of Candida tropicalis. Antimicrobial Agents and Chemotherapy, v.49, n.11, p.4608-4615, 2005.

VELASCO, M.C. Candidiasis and Cryptococcosis in birds. Seminars in Avian and Exotic Pet Medicine, v.9, n.2, p.7581,2000

WEIG, M.; BROWN, A.J.P. Genomics and the development of new diagnostics and anti-Candida drugs. Trends in Microbiology, v.15, p.310-317, 2007. 